\title{
TRADITIONS OF CERAMIC SHAPE'S MAKING AND ORNAMENTATION FOR THE POPULATION OF BRONZE AGE OF NORTHERN PART OF VOLGA-URAL: ABOUT DOMESTIC DEVELOPMENT DIRECTION
}

(C) 2016

O.D. Mochalov, doctor of historical sciences, rector, professor of the Chair of Domestic History and Archaeology Samara State University of Social Sciences and Education, Samara (Russia)

\begin{abstract}
The Volga-Urals population always took part in forming ceramic complexes of the Bronze Age. However the contribution they made to the genesis of the following traditions was unequal, differed in its extent and importance and was unequally revealed in technology, form making and decorating. All these factors could be traced the local specifics and particular artifacts. The neighboring population, especially the steppe one, was involved in the cooperation system, but the directions and intensity of contacts were corrected according to different factors and characteristics of the historic periods. The cooperation between the local and neighboring groups culturally close to each other was complicated by long distance communications, which resulted in drastic changes in some traditions, destabilization of skills at form making, emergence of some characteristics irrelevant to the previous times. It caused new cultural standards. The involvement of the northern Volga-Urals population in the system of long distance communications found its reflection in the wide expansion of traditions; especially in the early and late Bronze Age. The paper contains not only traditional typological results but also the results of special methods appliance of ceramic analysis: reveal of natural structure of forms, structural analysis of ornament, definition of the degree of proximity of ceramic complexes.

Keywords: Volga-Urals interfluve; Bronze Age; forest-steppe and the north of steppe; form and ornament of ceramics; typology; natural structure of forms; skills at form making; structural analysis of ornament; degree of proximity; Yamnaya culture; Poltavkinskaya culture; Potapovskiy type; Abashevo culture; Sintashta culture.
\end{abstract}

УДК 94 (367) : 929.5

\section{БРАК КОНСТАНТИНА МИХАЙЛОВИЧА И СОФЬИ ЮРЬЕВНЫ И ЕГО МЕСТО В ПОЛИТИЧЕСКИХ ОТНОШЕНИЯХ МОСКВЫ И ТВЕРИ В XIV ВЕКЕ} (C) 2016

С.Н. Абуков, кандидат исторических наук, старший преподаватель кафедры историографии, источниковедения, археологии и методики преподавания истории Донецкий национальный университет, Донеик (Донеикая Народная Республика)

Аннотация. Статья посвящена браку 1320 г. князя Константина Михайловича и княжны Софьи Юрьевны в драматический период московско-тверских отношений. Этот семейный альянс между Москвой и Тверью, который открыл череду браков между двумя правящими династиями в XIV-XV вв., не получил комплексного исследования со стороны историков. Автор анализирует обстоятельства и причины его заключения, а также определяет его влияние на политические отношения на Руси в XIV в. Отмечается, что родственный союз имел целью ослабить единство тверских князей. В статье уделено внимание спорному в научной литературе вопросу происхождения по материнской линии сыновей правившего в XIV в. в Твери князя Константина Михайловича, женатого дважды. Автор, сделав анализ имеющихся данных, устанавливает старшинство Константиновичей от разных браков отца и их предполагаемых матерей. Семейный конфликт между тверскими князьями имел значительные политические последствия для истории Тверского княжества и ее дальнейшей судьбы в борьбы с Москвой. В статье прослеживается спорная генеалогия их потомства. Отрицается, что дворяне Порошины могут быть потомками тверских князей, утративших титул.

Ключевые слова: Москва; Тверь; Кострома; Константин Михайлович; Софья Юрьевна; Юрий Данилович; Еремей Константинович; Семен Константинович; Дорогобужские; Чернятинские; Порошины; князь; брак; жена; сын; завещание; княжество; власть; политические отношения; происхождение; старшинство; владение.

Первая треть XIV в. - период длительной и жестокой борьбы в Северо-восточной Руси между двумя крупнейшими политическими центрами: Москвой и Тверью за титул великого князя владимирского, а фактически - за лидерство среди русских земель. Долгое время именно в споре Москвы и Твери происходила основная линия противостояния за гегемонию. Это был сложный процесс взаимодействия двух княжеств, где периоды смертельной вражды сменялись поисками компромисса и примирения. Браки представителей обоих княжеских линий являлись важнейшим индикатором колебания маятника политических отношений потомков Даниила Московского и Михаила Тверского. С другой стороны они становились элементом продолжения политики, только другими методами, не менее действенными, чем меч или договор.

Первым в серии браков, заключнных между представителями Тверского и Московского княжеских домов, стал брак 1320 г. третьего сына убитого в Орде Михаила Ярославича Тверского Константина с троюродной племянницей, дочерью великого князя владимирского и московского Юрия Даниловича Софьей. Это известие содержится в Рогожском летописце («Въ лето 6828 оженися князь Костянтинъ Михаилович [ь] оу великаго князя Юрїа Софїею, вен- 
чанъ бысть на Костроме въ Святомъ Феодоре») (орфография упрощена) [1, стб. 41]. Известие сохранилось в Тверском сборнике [2, стб. 413-414] и Никоновской летописи (без указания невесты) [3, с. 187]. Несмотря на важность этого родственного союза в московско-тверских отношениях XIV в. он не стал предметом особого исследования историков, рассматриваясь как штрих в общем контексте политических отношений между двумя политическими центрами Северо-восточной Руси.

Авторы фундаметальных дореволюционных работ ограничились простой констатацией брака или вовсе обошли его молчанием. Так, В.Н. Татищев упомянул сам брак Константина, но не назвал невесты [4, с. 79]. А.В. Экземплярский оставил интересные замечания о предполагаемых детях от этого брака [5, с. 479]. Что касается непосредственно политической составляющей причин брака, то в двух специальных трудах дореволюционного и нового времени, посвященных истории Тверского княжества В.С. Борзаковского и Э. Клюга союзу Константина и Софьи уделено немного внимания. Русский историк, высказавший отдельные интересные мысли в рамках рассматриваемой темы, тем не менее, не до конца был уверен, что Софья - дочь именно Юрия Даниловича [6, примечания с. 64]. Немецкий исследователь, сделавший то, что не удалось за 100 лет нескольким поколениям отечественных историков, со своей стороны сделал важные замечания о месте достижения соглашения о браке. Клюгу принадлежит и наиболее аргументированная характеристика правления Констнтина Михайловича в Твери [7]. В.А. Кучкин установил удельные владения Константина и его потомков, отметив сложность вопроса о матерях Константиновичей [8]. О причинах заключения этого родственного союза и его истинном организаторе определенно высказался Л.В. Черепнин [9, с. 473]. Внимание проблемам времени свадьбы, Костроме как ее месте и возможных мотивах Юрия Московского уделил Н.С. Борисов [10, с. 107-109]. Тем не менее, этот семейный альянс нуждается в комплексном анализе в контексте политических отношений на Руси в перв. пол. XIV в. Кто стал инициатором брака, какие цели он преследовал и какое оказал влияние на московскотверские отношения, время его заключения, выбор места свадьбы, вероятное потомство от этого брака вот круг тех вопросов, ответ на который мы попытаемся найти.

Итак, в результате московско-ордынских интриг в 1318 г. великий князь владимирский и тверской Михаил Ярославич был казнен в Орде ханом Узбеком. Его тело, сын-отрок Константин, находившийся с отцом при кочующем дворе хана и бояре достались как трофеи его сопернику московскому князю Юрию Даниловичу, получившему от Узбека ярлык на великое княжение владимирское. Летописи сообщают о возвращении Юрия на Русь в следующем 1319 г. [11, c. 114].

Однако этим конфликт с преемником Михила тверским князем Дмитрием Михайловичем с характерным прозвищем «Грозные очи» был далеко не исчерпан. Вдова и сыновья убитого не имели достоверных данных о судьбе Михаила, и узнав о возвращении Юрия Даниловича («се уведавши»), отправили делегатов в Москву узнать наверняка. Только после точного известия о казни, началась скорбь («плакахуся на многы дни неутешно») [12, с. 198]. Необходимо было решить вопрос о возвращении в Тверь тела убитого и отпуска пленных. Тверская княжеская семья непременно желала получить его останки для торжественного перезахоронения на родине. Вопрос требовал новых переговоров с Москвой. Весьма возможно, что волновались и за Константина, зная нрав московского князя, которому ранее ничего не стоило убить в Москве тверского посла Алексу Марковича и рязанского князя Константина Романовича [13, с. 8687; 2, стб. 410]. Уполномоченным на переговорах от Твери стал второй сын казненного Александр Михайлович. Как видно, старший Дмитрий Михайлович уклонился от прямого контакта с Юрием Московским, поэтому на семейном совете, как отмечает Ермолинская летопись, и было решено, что на переговорах тверскую сторону представит князь Александр $[14$, c. 101]. Последний, только после гарантий безопасности со стороны ростовского владыки Прохора, доверенного лица митрополита Петра и князя Ярослава Стародубского, лично прибыл во Владимир и заключил мир с Юрием Даниловичем. Затем летописи сообщают о выдаче тела казненного Михаила в Тверь, торжественно погребенного в родном городе 6 сентября, потом - тела второй жены Юрия Кончаки-Агафьи, которую отправили на перезахоронение не в Москву, как можно было ожидать, а в Ростов, откуда происходила первая жена Юрия (1319 г.) [15, стб. 395-396; 11, с. 106].

Как отмечалось, брак между Константином и Софьей был заключен в 1320 г. Можно подумать, что тверские князья нуждались в передышке и не были готовы к продолжению конфронтации с Москвой. Формально жених просил руки невесты, а согласие давали старшие родичи. Юрий Данилович со своей стороны мог быть заинтересован в ослаблении противостояния с Тверью в свете необходимости укрепления своей власти на Руси, вокняжении в Новгороде, налаживании выплаты ордынской дани. В этом году летописи кратко сообщили об очередном московском походе на Рязань [16, с. 338].

Однако ключ к решению причин заключения брака вероятно был в ином. Э. Клюг предположил, что соглашение о нем было достигнуто ранее в ходе переговоров Юрия с Александром во Владимире [7, c. 114]. Московский князь был хозяином положения и диктовал свои условия тверским князьям, о чем согласно говорят летописи («и едва умоливше кн(я)зя великаго Юрья Даниловича» [13, стб. 395; 11, с. 114; 12, с. 197]. Никоновская летопись также пишет, что тверичи «просяше тела съ молениемъ и со слезами» [3, с. 186]. С.М. Соловьев констатировал, что мир был подписан на условиях московского князя [17, c. 217]. В.С. Борзаковский, говоря о причинах московско-тверского брака, отметил только, что «Московский князь при этом имел свои расчеты», не пояснив своей мысли [6, с. 118]. О доминировании Москвы «в тот момент» пишет и Л.В. Черепнин [9. с. 473]. Н.С. Борисов предположил, что брак был условием освобождения Константина. Его цель - «расколоть дружную когорту тверских Михайловичей, перетянуть на сторону Москвы хотя бы одного из них» [10, с. 108]. 
Очевидно, что брак был навязан Твери московским князем, а заключение родственных союзов с младшими представителями Тверского княжеского дома в дальнейшем станет для московских князей эффективным инструментом по ослаблению главного соперника путем подрыв «одиначества» местных князей с целью установления там своего влияния. Видимо, юный Константин как никто из Михайловичей подходил для этой роли. При этом у нас нет прецедента, чтобы хан вмешивался внутридинастические матримониальные планы русских князей. В то же время трудно считать, что планом Юрия было установление контроля над тверским правительством, как полагал Л.В. Черепнин («Стремясь держать под своим контролем тверское правительство, Юрий принял меры к тому, чтобы сделать своим подручным князя Константина Михайловича тверского, и в этих целях устроил его брак со своей дочерью Софьей») [9, с. 473]. Не Константин и его бояре, а мать княгиня Анна и старшие братья Михайловичи со своими советниками в тот период определяли тверскую политику. Б.Н. Флоря обратил внимание [18, с. 57], а В.А. Кучкин обосновал предположение, что Константин Михайлович владел не гипотетическим Дорогобужским уделом, которого не существовало в природе на территории Тверского княжества, а был клинским князем [8, с. 181-184]. Его удельные владения наиболее близко подходили к Московскому княжеству, что также имело значение.

Юрий хорошо лично знал своего тверского пленника, приведенного из Орды. Можно предположить, что жених и невеста также были знакомы во время длительного пребывания Константина в плену у будущего тестя в Москве [19, с. 226]. Впрочем, это не играло большой роли в таких союзах, где главной была политическая составляющая. Как бы там ни было, но Юрий отдал в ненавистную Тверь единственную известную нам дочь. Летописи опять-таки замолчали подробности брачных торжеств. По обычаю свадьбы обычно проходили в стольных городах семьи жениха и невесты. Иногда, как было со свадьбой Александра Невского в 1239 г., ее отпраздновали на полпути между Полоцким, Новгородом и Владимиром - в смоленском Торопце [16, стб. 300]. На этот раз местом торжеств была избрана отдаленная Кострома, которая, вероятно, стала неким компромиссом между сторонами, хотя контролировалась Юрием Даниловичем как великим князем владимирским. Свадьба состоялась только осенью 1320 г. [7, с. 114, 147]. Мнение о заключении брака в начале года не подтверждается источниками [10, с. 107]. Константин, вероятно, достиг к тому времени брачного 14тилетнего возраста. Дело в том, что известие о его рождении помещено под 1306 г. [3, с. 176]. В Рогожском летописце оно также отнесено к 6814 г., но объединен к сообщением о смерти великого князя Андрея Александровича, проишедшей двумя годами ранее [1, стб. 35]. На торжества по традиции должны были съехаться представители обеих семей и гости, но как это было на самом деле - мы не знаем. Трудно не согласиться с версией, что только после этого Константин был отпущен домой [8, с. 190]. Как можно убедиться, этот брак не привел к улучшению отношений между Москвой и Тверью. Перемирие продлилось недолго, и уже в 1321 г. произошел новый конфликт, в ходе которого Юрий Московский двинулся походом на тверские земли $[16$, стб. $396 ; 17$, 338; 12, с. 198]. Тем самым становится очевидным, что брак Константина и дочери Юрия не смог надолго повлиять на улучшение отношений между сторонами, так как Москва и не ставила такой задачи, кроме усиления своих позиций в тверской правящей элите.

После бегства брата Александра Михайловича во время карательной Федорчуковой рати, Константин при поддержке Ивана Калиты стал тверским князем в 1328 г., который занимал с перерывом в 13361339 гг. до смерти в 1345 г. [1, стб. 45, 51, 57; 7, c. 122,159$]$. Э. Клюг справедливо отметил, что родство с московскими князьями оказалось теперь выгодно Константину [7, с. 121]. Это был покладистый правитель, который следовал за Иваном Калитой [1, стб. 44; 16, с. 403]. Как образно выразился А.В. Экземплярский: «Константин шел за Калитой, как бы на привязи» [5, с. 477]. Московский князь приходился ему не только троюродным братом, но и дядей жены. В.С. Борзаковский полагал, что в свое второе правление, он оставался в тени [6, с. 131]. Но Клюг, поанализировав данные летописей, отметил, что с рубежа 30-x-40-х гг. XIV в. Константин уже не был таким безропотным. Он не только консолидировал Тверское княжество, но и отстаивая его независимость от посягательств Москвы [7, с. 159-163]. Отметим, как правнук, внук, сын и брат великих князей владимирских, он имел права на этот титул, но так и не решился открыто оспорить власть у Семена Гордого.

Софья Юрьевна умерла раньше мужа. Об этом можно судить потому, что скончавшаяся во время эпидемии чумы в 1365 г. вдова князя Константина носит другое имя - Евдокия [1, стб. 79]. Она, как жена Константина упоминается уже в 1339 г. [7, с. 147]. Когда же умерла первая жена Софья - не известно. Трудно согласиться, что ее брак с Константином был расторгнут, что было вещью чрезвычайной, а упоминаемая в 1358 г. бабка тверского княжича Александра Михайловича из другой линии Твеского дома - это Софья Юрьевна. Очевидно, что речь идет о вдове Михаила Ярославича Анне (в монашестве Софье) $[20$, с. 302-304; 3, с. 230]. Возможно, что тесные контакты Москвы и Твери при Калите в 30-е гг. $\mathrm{XIV}$ в. подкреплялись связью с родственниками жены, а смерть Софьи способствовала охлаждению прежних отношений.

У князя Константина известны два сына с нехарактерными для Тверского дома именами: бездетный, хотя и женатый, Семен, умер в 1365 г. и Еремей, умер 1373 г. (последнее имя вообще уникально среди русских князей) [1, стб. 79; 21, с. 19]. Но кто из Константиновичей был старше и предполагаемым внуком Юрия Даниловича Московского? «Бархатная книга» первым называет Семена Константиновича [22]. Мнение историков и генеалогов разделились $[23$, с. $254 ; 24$, с. $108 ; 17$, с. $328 ; 7$, с. 390$]$. В известии о поездке в Орду именно Семен сопровождал дядю Василия Михайловича [1, стб. 72]. Однако, важнейший источник - жалованная грамота тверскому Отрочу монастырю ок. 1364 г., перечисляя местных князей в их иерархическом старшинстве, дважды называет другой порядок Константиновичей: сначала Еремей, затем Семен [25, с. $152 ; 26$, р. 46-47; 8, 
c. 171]. Это документальное свидетельство важнее родословных, где нередко безпотомственные князья оказывались не на своем месте или вообще опускались. В 1372 г. Еремей Константинович уже имел сына Дмитрия, достаточно взрослого, чтобы участвовать в военном походе [1, стб. 98]. Конечно, известны случаи, когда князья участвовали в походах в очень раннем возрасте, как было с дядей Еремея Дмитрием Михайловичем в 1311 г. [13, с. 87]. Однако эти примеры сравнивать буквально нельзя, так как разными были цели участия князей в боевых действиях. Вероятно, что Еремей родился во второй половине 20-х первой половине 30-х гг. XIV в. Каждый из братьев Константиновичей имел свое отдельное владение, унаследованное от отца.

Историки еще в XIX в. высказали предположение, что у братьев были разные матери [5, с. 478]. На эту мысль их натолкнул тот факт, что Константиновичи, похоже, находились в неприязненных отношениях. По крайней мере, Семен «а отчины своея уделъ и княгиню свою приказаль князю великому Михаилу Александровичю», в обход брата Еремея [1, стб. 79]. А.Е. Пресняков сомневался, что имело место оформление передачи владений завещанием в вотчину, вместо этого подозревая Михаила в захвате княжества Семена [27, с. 146]. С одной стороны, если б имел место только грубый захват, то вопрос не породил в дальнейшем такую острую правовую коллизию. С другой, придется представить на основании летописной фразы, что Семен завещал двоюродному брату не только удел, но и жену.

В.А. Кучкин, комментируя гипотезу о разных матерях Константиновичей, отметил: «Но указанное соображение надо рассматривать как просто догадку, серьезно аргументировать ее невозможно» [8, с. 182]. Вопрос в справочной научной литературе остается запутанным и сегодня [28, с. 400, 594]. Однако по нашему мнению, в пользу того, что младший Семен сын именно второй жены Евдокии говорит их совместная смерть от чумы. Как известно, заражение происходило при контакте близких родственников. Рогожский летописец весьма четко описывает смерть в семьях тверских князей в 1365 г.: вдова Александра Михайловича княгиня Настатья, ее младший сын с женой; старший сын холмский князь Всеволод и его жена Софья, а также «княгини Овдотїа Костянтинова, а потомъ князь Семенъ Костянтинович [ь]» $[1$, стб. 79]. Представляется, что последнее летописное известие говорит о смерти матери и сына. У нас нет других причин, кроме как предположить семейный владельческий конфликт, характерный для тверских князей в 40-е-70-е гг. XIV в., который заставил князя Семена обойти родного брата в пользу двоюродного. Какова его причина - определить трудно, но в источниках можно отметить важность на Руси факта рождения княжеских детей от разных матерей [2, стб. 151; 29, с. 19]. Любопытно, что князья довольно редко добровольно отказывали свои уделы другим родичам мимо прямых наследников $[12$, с. $183 ; 5$, c. 547,605$]$.

Дальнейшие перипетии московско-тверских отношения в связи с борьбой за выморочный удел Семена Константиновча в 60-е годы XIV в. не раз становились объектом исследования и подробного описания, поэтому нет смысла подробно останвиваться.
Напомним, что Еремей Константинович «бегал» в Москву, то есть, пытался опереться на ее поддержку в своей борьбе с Михаилом Тверским. Вместе с московскими полками и дядей Василием Михайловичем, сватом умершего Семена Гордого, князь Еремей воюет в тверских волостях. В последние годы жизни его пыл несколько спал и он вынужден был признать верховную власть двоюродного брата Михаила Тверского (его сын действует уже на стороне Михаила Тверского) [1, стб. 81, 84, 85, 90, 98; 21, с. 19]. Известна жена Еремея по имени Анастасия (умерла осенью 1407 г.) и помимо Дмитрия, умершего в том же году, еще один сын Иван Еремеевич, участвовавший в походе союзной москвичам тверской рати против литовцев в 1406 г. [2, стб. 475; 21, с. 197].

С большой долей вероятности Еремей Константинович мог быть внуком Юрия Московского по матери. Тогда единственными его потомками следует признать Дорогобужских и Чернятинских князей. Как удельные князья Тверского дома, они известны в $\mathrm{XV}$ в. Великий князь тверской Иван Михайлович в 1408 г. женился вторым браком на внучке Еремея Евдокии Дмитриевне, приходившейся ему троюродной племянницей. Это первый брак внутри Тверского княжеского дома, видимо связаный с желанием укрепить единство двух существующих линий местной династии: Александровичей и Константиновичей. Подобные внутрисемейные браки характерны в XV в. и для князей Московского дома. Евдокия Дмитриевна рано умерла (13 апреля 1411 г.). В известии о ее смерти Никоновская летопись добавляет, что она была второй дочерью Дмитрия Еремеевича, но ничего не сообщает о ее сестре [21, с. 203, 215].

Правнук Еремея князь Осип Андреевич Дорогобужский был женат на княжне Анастасии Михайловне Верейской, правнучке Дмитрия Донского, и по этому браку находился в свойстве с князьями Московского дома. Незадолго до падения независимости Тверского княжества, в 1485 г. князь Осип Дорогобужский перешел на службу к Ивану III и влился в ряды московской феодальной элиты (некоторое время он был наместником Ярославским) [29, с. 310; 24, c. 108]. Его внуки князья Иван и Дмитрий (сыновья Ивана Пороши Дорогобужского) в «Бархатной книге» показаны бездетными [22]. Иван Иванович в юном возрасте, как пишет князь Андрей Курбский, стал одной из первых жертв Ивана Грозного [30, c. 7]. Его имя писано в синодик Успенского Московского собора $[31$, с. 449]. В сер. XVI в. род князей Дорогобужских пресекся.

Маловроятно, чтобы дворяне Порошины имели отношение к тверским князьям, как полагали некоторые исследователи [23, с. 254]. В их родовом гербе нет и намека на княжеское происхождение [32]. Ономастически также не видно преемственности от Тверского дома Рюриковичей. В 1584 г. городовые дворяне Григорий, Феоктист и Богдан Федоровы дети Порошины были поверстаны денежным окладом [32]. В том же веке угас и род князей Чернятинских, которые не занимали видного положения и ничем не прославились на службе у старицких князей [24, с. 111].

Подводя краткий итог, отметим, что брак Константина Михайловича и Софьи Юрьевны стал первым в череде московско-тверских браков и одним из важных эпизодов взаимоотношений двух русских кня- 
жеств. Родственный союз был навязан Твери Москвой. Это была первая попытка Москвы путем брачных уз усилить свое влияние на территории своего заклятого противника. Брак характеризует всю сложность и драматизм отношений сторон, когда в следующем году Москва и Тверь возобновили противостояние. О первой жене Константина Софье Юрьевне больше ничего не известно, кроме того, что она умерла раньше мужа. Традиционный взгляд на Константина Михайловича во главе Тверского княжества, как на послушного правителя, ничем не досаждавшего Москве, верно только отчасти. Что касается сыновей Константина, то старшим был именно Еремей, а не Семен, как часто считается в генеалогии. Матерью Семена была вторая жена его отца княгиня Евдокия. Вероятно, что Еремей был сыном Софьи Юрьевны. Его потомки - удельные, а затем служилые Дорогобужские и Чернятинские князья, угасли без мужских потомков в XVI в.

\section{СПИСОК ЛИТЕРАТУРЫ:}

1. Полное собрание русских летописей. Т. XV (Вып. 1). М.: Наука, 1965.

2. Полное собрание русских летописей. T. XV. М.: Наука, 1965.

3. Полное собрание русских летописей. Т. 10. М.: Наука, 1965.

4. Татищев В.Н. История Российская. Т. 5. М.-Л.: Наука, 1965. 343 с.

5. Экземплярский А.В. Великие и удельные князья Северной Руси в татарский период с 1238 по 1505 гг. Т. 2. СПб.: Типография Императорской Академии наук, 1891. 696 с.

6. Борзаковский В.С. История Тверского княжества. СПб.: Издание книгопродавца И.Г. Мартынова, $1876.437 \mathrm{c}$.

7. Клюг Э. Княжество Тверское (1247-1485). Тверь: РИФ Лтд., 1994. 432 с.

8. Кучкин В.А. Формирование государственной территории Северо-Восточной Руси в X-XIV вв. М.: Наука, 1984. 350 с.

9. Черепнин Л.В. Образование Русского централизованного государства. М.: Издательство социально-экономической литературы, 1960. 899 с.

10. Борисов Н.С. Иван Калита. М.: Молодая гвардия, 2005. 302 с.

11. Полное собрание русских летописей. T. XXIV. М.: ЯРК, 2000. 288 с.

12. Полное собрание русских летописей. Т. VII. М.: ЯРК, 2001. 360 с.

13. Полное собрание русских летописей. Т. 18. СПб.: Типография М.А. Александрова,, 1913. 316 с.
14. Полное собрание русских летописей. Т. ХХІІІ. М.: ЯСК, 2004. 256 c.

15. Полное собрание русских летописей. T. VI (Вып. 1). М.: ЯРК, 2000. 320 с.

16. Полное собрание русских летописей. Т. III. М.: ЯРК, 2000. $720 \mathrm{c}$.

17. Соловьев С.М. История России с древнейших времен. Кн. ІІ. М.: Мысль, 1988. 765 с.

18. Флоря Б.Н. Об одном из источников «Трактата о двух Сараматиях» Матвея Меховского // Советское славяноведение. М.: Наука, 1965. № 2. С. 55-61.

19. Абуков С.Н. Первые московские князья. Ростов-на-Дону: Феникс, 2012. 430 с.

20. Аверьянов К.А. Купли Ивана Калиты: источниковедческие проблемы процесса объединения русских земель XIV в.: дис. ... д-ра ист. наук. М., 2001. $339 \mathrm{c}$.

21. Полное собрание русских летописей. Т. 11. М.: Наука, 1965.

22. Бархатная книга. Глава 7 [Электронный реcypc] // http://genealogia.ru/projects/barhat/7.htm.

23. Петров Н.П. История родов русского дворянства. Т. 1. М.: Современник, 1991. 431 с.

24. Зимин А.А. Формирование боярской аристократии в России. М.: Наука, 1988. 350 с.

25. Акты социально-экономической истории Северо-Восточной Руси. Т. III. М.: АН СССР, 1964. 688 с.

26. Baumgarten de N. Des Branches Regnantes de Rurikides du XIII-e au XVI-e siècle // Orientalia Christiana. Roma, 1934. T. XXXV-1.

27. Пресняков А.Е. Образование Великорусского государства. М.: Богородский печатник, 1998. 496 с.

28. Славянская энциклопедия Т. 1. / под ред. В.В. Богуславского. М.: ОЛМА-ПРЕСС, 2002. 784 с.

29. Духовные и договорные грамоты великих и удельных князей. М.-Л.: АН СССР, 1950. 585 с.

30. Устрялов Н. Сказания князя Курбского. СПб.: Типография Императорской академии наук, 1868. $494 \mathrm{c}$.

31. Древняя Российская Вивлиофика, содержащая в себе: собрание древностей Российских, до истории, географии и генеалогии российской касающихся, изданная Николаем Новиковым, членом вольного Российского собрания при имп. Московском университете, издание 2-е, вновь исправленное, умноженное и в порядок хронологический по возможности приведенное. Ч. 6. СПб.: Типография компании типографической, 1788.514 с.

32. Общий гербовник дворянских родов Всероссийской империи. Ч. 6. С. 34 [Электронный ресурс] // http://gerbovnik.ru/og/v6/p0083.jpg.

\section{THE MARRIAGE OF KONSTANTIN MIHKAILOVICH WITH SOPHIA YURIEVNA AND ITS SIGNIFICANCE IN POLITICAL RELATIONS BETWEEN MOSCOW AND TVER' IN THE XIV CENTURY}

(C) 2016

S.N. Abukov, candidate of historical sciences,

senior lecturer of the Chair of Historiography, Source Studies, Archeology and Methods of Teaching History Donetsk National University, Donetsk (Donetsk People's Republic)

Abstract. The article is devoted to the marriage of prince Konstantin Mihkailovich with princess Sophia Yurievna in 1320 and its place in dramatic period relations between Moscow and Tver' relations. This family-run alliance between Moscow and Tver, which opened the series of marriages between the two ruling dynasties in the XIV-XV cen- 
turies, has not received comprehensive study by historians. The author made an analysis of the reasons and consequences of this marriage, and its influence on policy in Rus' in the XIV century. The article is devoted to the origin in the maternal line of sons Tver' Prince Konstantin Mikhailovich's sons due to tha material line, who ruled in the XIVth. century and who was married twice. This problem is controversial in scientific literature. The author made the analysis of the available data sets the precedence of Konstantin's sons from different marriages and their assumed mothers. Family conflict between the princes of Tver' had significant political consequences for the history of the Tver' Principality and its subsequent destiny in struggle with Moscow. The author tries to determine their posterity. It is denied that the nobles Poroshins can be the descendants of the princes of Tver', who lost the title.

Keywords: Moscow; Tver'; Kostroma; Konstantin Michailovich; Sophia Yurievna; Yuriy Danilovich; Eremey Konstantinovich; Semyon Konstantinovich; Dorogobuzhsky; Chernyatinsky; Poroshins; prince; marriage; wife; son; dynasty; principality; power; political relations; origin; seniority; possession.

УДК 94(47).08

\title{
К ВОПРОСУ ПЕРИОДИЗАЦИИ ИСТОРИИ ЛАЗАРЕВСКОГО ИНСТИТУТА ВОСТОЧНЫХ ЯЗЫКОВ
}

(C) 2016

\author{
В.Р. Аветисян, аспирант кафедры культурологии и искусств \\ Северо-Кавказский федеральный университет, Ставрополь (Россия)
}

\begin{abstract}
Аннотация. Проблема периодизации исторического события или явления всегда имеет дискуссионный характер. Иногда трудно найти единое мнение в вопросе определения хронологических временных рамок того или иного события. Не осталась в стороне и проблема периодизации истории Лазаревского института восточных языков. Лазаревский институт имел богатую и порой запутанную историю, поэтому одно и то же историческое событие в жизни учебного заведения можно интерпретировать по-разному. Исследователями в разные периоды (в дореволюционный период - А. Зиновьев, в советский период - А.П. Базиянц, М. Нерсисян и А.Т. Амирханян, в современной отечественной историографии - А.В. Торкунов, В.В. Василенко) разрабатывались различные варианты периодизации: проводилось разделение на более мелкие временные отрезки или объединение в более крупный период событий, тесно переплетенных между собой. В основе периодизации каждого историка лежит принцип, по которому он характеризует историческое событие. Вариант периодизации, представленный автором статьи, дает возможность рассмотреть вопрос по-новому, так как включает в хронологические рамки период, предшествующий началу преподавания в институте. Это период, сыгравший значительную роль не только в открытии, но и в формировании устоев и принципов образовательного учреждения на протяжении всего его существования.

Ключевые слова: периодизация; образование; Лазаревский институт восточных языков; И.Л. Лазарев; Армянское училище; Москва; Петербургский университет; Московский государственный институт международных отношений; русско-армянские отношения; высшее образование; А.В. Торкунов; дискуссия.
\end{abstract}

В 2015 г. в России и Армении широко отмечали юбилейную дату - 200-летие образования Института восточных языков (Лазаревского института), деятельность которого способствовала развитию русскоармянских отношений. В Ереване прошел, приуроченный к этой дате, III Международный форум выпускников МГИМО, на который собрались представители разных стран, получивших образование в институте. Это, в частности, ректор МГИМО А.В. Торкунов, министры иностранных дел, политические деятели. К участникам форума обратился Президент России В.В. Путин: «...Лазаревский институт восточных языков - предшественник МГИМО, стал символом научных, культурных, интеллектуальных и духовных связей России и Армении» [1]. С приветственным словом выступил президент Армении С.А. Саргсян. На форуме были организованы дискуссии по актуальным темам, таким как интеграционные вопросы в мире, Ближний Восток, экономическая дипломатия. Министр иностранных дел России С.В. Лавров в своем докладе, подчеркивая значение Лазаревского института, отметил: «Традиции подготовки высококлассных специалистов-международников берут начало в Лазаревском институте» [2]. А в Москве в честь юбилейной даты в МГИМО была ор- ганизована выставка, в открытии которой принимал участие выпускник МГИМО, министр иностранных дел Армении Э.А. Налбандян.

Нельзя обойти вниманием событие, которое предшествовало юбилейному мероприятию. В 2011 г. в Ставропольском государственном университете, на кафедре культурологии, при поддержке Российского гуманитарного научного фонда, прошел научный круглый стол «Роль Института восточных языков (Лазаревского института) в деле упрочения русскоармянских культурных отношений». Круглый стол был посвящен истории возникновения, основным этапам деятельности Лазаревского института. Был выпущен сборник материалов круглого стола.

Лазаревский институт восточных языков стоял в одном ряду с «наиболее значительными учебными заведениями Москвы» [3, с. 342], такими как Московский университет, Петровская сельскохозяйственная академия, Высшее техническое училище, Консерватория, что свидетельствует о том, что данное учебное учреждение пользовалось авторитетом в Российской империи и оказывало заметное влияние как на развитие русско-армянских отношений, так и на создание фундаментального пласта дипломатов для работы с странами Востока. 